\section{Luminescence from Hexacyanoruthenate(III)}

\section{A. VOGLER and H. KUNKELY}

Universität Regensburg, Institut für Chemie, D-8400 Regensburg, F.R.G.

Received November 12,1980

Luminescence of molecular transition metal complexes originating from ligand field (LF), metal-toligand charge-transfer (MLCT) or intraligand (IL) excited states is well known [1]. In contrast, emission from ligand-to-metal charge-transfer (LMCT) excited states has not yet been reported to our knowledge*. The reason for this lack is not quite clear. However, it seems likely that most complexes, which have lowenergy LMCT excited states, have even lower-lying LF-states, but only the lowest excited state of a complex may emit.

A complex with a LMCT state as lowest excited state should be composed of a strongly oxidising metal with a large LF splitting and strongly reducing ligands with a high LF strength. For the present study we selected the complex $\left[\mathrm{Ru}(\mathrm{CN})_{6}\right]^{3-}$ which seems to meet these requirements best.

The absorption spectrum (Fig. 1) of $\left[\mathrm{Ru}(\mathrm{CN})_{6}\right]^{3-}$ [2] shows low-energy bands which we assign to LMCT transitions. In analogy to $\left[\mathrm{Fe}(\mathrm{CN})_{6}\right]^{3^{--}}$[3] the lowest-energy band of $\left[\mathrm{Ru}(\mathrm{CN})_{6}\right]^{3-}$ (shoulder at $21050 \mathrm{~cm}^{-1}, \epsilon=875$ ) is assigned to the LMCT transition ${ }^{2} \mathrm{~T}_{2 \mathrm{~g}} \rightarrow \mathrm{a}^{2} \mathrm{~T}_{\mathrm{lu}}$. LF bands are expected to occur at much higher energies. $\left[\mathrm{Ru}(\mathrm{CN})_{6}\right]^{4-}$ which has a smaller ligand field splitting due to the lower oxidation state of the metal [4], shows an extremely weak, lowest-energy absorption at $31000 \mathrm{~cm}^{-1}(\epsilon=$ 0.1 ) which was assigned to the spin-forbidden $L F$ transition ${ }^{1} \mathrm{~A}_{1 \mathrm{~g}} \rightarrow{ }^{3} \mathrm{~T}_{1 \mathrm{~g}}$ [5].

The emission spectrum of $\left[\mathrm{Ru}(\mathrm{CN})_{6}\right]^{3-}$ consists of a single band with a maximum at $19050 \mathrm{~cm}^{-1}$ (Fig. 1) which was independent of the excitation wavelength between 302 and $436 \mathrm{~nm}$. Since this band overlaps with the lowest-energy absorption we conclude that the emission comes from the lowest LMCT excited state. The relatively small Stokes shift of $2000 \mathrm{~cm}^{-1}$ is consistent with this assignment because

*Emission from mixed oxides containg $\mathrm{d}^{0}$ metals as Ti(IV), $\mathrm{Zr}(\mathrm{IV}), \mathrm{V}(\mathrm{V}), \mathrm{Nb}(\mathrm{V}), \mathrm{W}(\mathrm{VI})$ has been reported and may be of the LMCT type. But the emission is a solid state property not associated with molecular complexes. See for example: G. Blasse, in 'Luminescence of Inorganic Solids', B. Di Bartolo, Ed., Plenum Press, New York, 1978, p. 457.

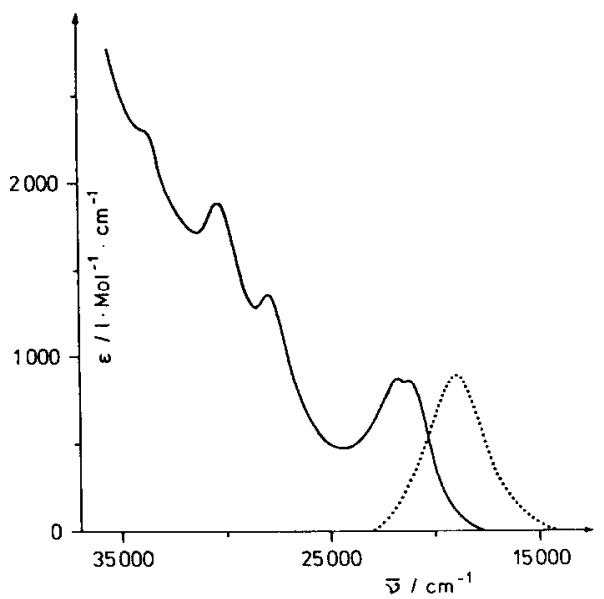

Fig. 1. Electronic absorption and emission (dashed line) spectra of $\left[\left(\mathrm{C}_{2} \mathrm{H}_{5}\right)_{4} \mathrm{~N}\right]_{3}\left[\mathrm{Ru}(\mathrm{CN})_{6}\right]$ in ethanol; absorption at $298 \mathrm{~K}$, emission excited at $366 \mathrm{~nm}$ and $77 \mathrm{~K}$ (intensity in arbitrary units).

the antibonding $e_{\mathrm{g}}$ orbitals are not involved in this ${ }^{2} \mathrm{~T}_{2 \mathrm{~g}} \leftrightarrow \mathrm{a}^{2} \mathrm{~T}_{1 \mathrm{u}}$ transition. The very short emission lifetime $(0.5 \mathrm{nsec})$ is in agreement with a spin- and parity-allowed transition. A LF assignment for this emission is unlikely for several reasons. Since an emission from the lowest LF excited state of $[\mathrm{Ru}$ $\left.(\mathrm{CN})_{6}\right]^{3-}$ would be a spin-forbidden (quartet $\rightarrow$ doublet) transition it should be much longer living. In addition, $\left[\mathrm{Ru}(\mathrm{CN})_{6}\right]^{4-}$ shows a $\mathrm{LF}\left({ }^{3} \mathrm{~T}_{1 \mathrm{~g}} \rightarrow{ }^{1} \mathrm{~A}_{1 \mathrm{~g}}\right)$ emission at $22650 \mathrm{~cm}^{-1}$ [5]. The occurrence of a $\mathrm{LF}$ emission of $\left[\mathrm{Ru}(\mathrm{CN})_{6}\right]^{3-}$ at lower energies would be difficult to explain.

An attempt to detect the analogous luminescence from the lowest LMCT excited state of $\left[\mathrm{Fe}(\mathrm{CN})_{6}\right]^{3-}$ was not successful. It is assumed that a non-emitting LF state, which lies below the lowest LMCT state quenches the CT emission. Such an inversion of the lowest, thermally equilibrated LF and LMCT excited states would be not surprising, since the lowest LMCT band of $\left[\mathrm{Fe}(\mathrm{CN})_{6}\right]^{3-}$ occurs at higher energies $\left(23500 \mathrm{~cm}^{-1}[3]\right)$ than that of $\left[\mathrm{Ru}(\mathrm{CN})_{6}\right]^{3-}$ consistent with the smaller oxidizing power of $\left[\mathrm{Fe}(\mathrm{CN})_{6}\right]^{3-}[6]$. On the contrary, the LF splitting of $\mathrm{Fe}$ is smaller than that of $\mathrm{Ru}[4]$.

\section{Acknowledgements}

Financial support for this research by the Deutsche Forschungsgemeinschaft and the Fonds der Chemischen Industrie is gratefully acknowledged. 


\section{References}

1 G. A. Crosby, Acc. Chem. Res., 8, 231 (1975).

2 A. Vogler, W. Losse and H. Kunkely, J. Chem. Soc. Chem. Comm., 187 (1979).

3 J. J. Alexander and H. B. Gray, J. Am. Chem. Soc., 90, 4260 (1968).
4 C. K. Jфrgensen, Oxidation Numbers and Oxidation States, Springer-Verlag, Berlin, 1969.

5 M. Mingardi and G. B. Porter, Spectrosc. Lett., I, 293 (1968).

6 D. D. DeFord and A. W. Davidson, J. Am. Chem. Soc., 73, 1469 (1951). 